\title{
Makna Frasa "Orang-Orang Terpilih" Dalam Upaya Mengembangkan Daya Tahan Terhadap Resiliensi: 1 Petrus 1:1-2
}

\author{
Desti Samarenna \\ Sekolah Tinggi Teologi Internasional Harvest Semarang \\ e-mail: destisamarenna@gmail.com
}

\begin{abstract}
Understanding a relationship with God properly enables experiencing true spiritual growth. The purpose of writing this scientific paper are: First, believers understand their position as the elect. Second, explaining based on the text of 1 Peter 1:12 as the chosen people are able to withstand pressure in facing life's circumstances. This article is a research that applies the text analysis method, especially 1 Peter 1:1-2 which discusses the chosen people. The results of the discussion show that believers as chosen people continue to strive to develop resistance to suffering by realizing that as the chosen people their nature is eternal, not temporary so that they behave holy and faithful in order to live in peace and be able to answer all slander and loopholes. from unbelievers. Believers face suffering (resilience) so that they are patient and persevere in the faith, so that all persecution and calamities that befall them do not turn them away from Christ and the gospel.
\end{abstract}

Keywords: Resilience, Immigrants, Elected, Blood Splash, Grace And Peace Damai

\begin{abstract}
Abstrak: Memahami hubungan dengan Allah secara benar memampukan mengalami pertumbuhan rohani yang benar. Tujuan penulisan karya ilmiah ini adalah: Pertama,orang-orang percaya memahami posisinya sebagai orang-orang pilihan. Kedua, menjelaskan berdasarkan teks 1 Petrus 1:1-2 sebagai orang-orang terpilih mampu bertahan dalam tekanan dalam menghadapi keadaan hidup. Artikel ini merupakan penelitian yang menerapkan metode analisis teks, khususnya 1 Petrus 1:1-2 yang membahas tentang orang-orang terpilih. Hasil dari pembahasan didapatkan bahwa, orang percaya sebagai orang-orang pilihan terus berupaya mengembangkan daya tahan terhadap penderitaan dengan cara menyadari sebagai orang-orang pilihan sifatnya kekal bukan sementara sehingga berperilaku kudus dan setia agar tetap hidup dalam damai sejahtera dan mampu menjawab segala fitnah dan celah dari orang-orang yang tidak percaya. Orang percaya menghadapi penderitaan (resiliensi) supaya bersabar dan bertekun dalam iman, agar segala penganiayaan dan malapetaka yang menimpa tidak sampai membuat mereka murtad dari Kristus dan Injil.
\end{abstract}


HARVESTER: Jurnal Teologi dan Kepemimpinan Kristen, Vo 16, No 1, (Juni 2021)

Kata Kunci: Resiliensi, Orang-Orang Pendatang, Terpilih, Percikan Darah, Anugerah dan Damai Sejahtera

\section{PENDAHULUAN}

Istilah resiliensi berasal dari kata latin resilire, yang berarti melambung kembali. Kapaitas merespon secara positif ketika berhadapan dengan kesengsaraan. Kemampuan individu berresiliensi pada masa-masa yang sulit. Faktor religius adalah faktor yang menyangkut transendensi seseorang mengenai suatu permasalahan hidupnya pada Tuhan. ${ }^{1}$ Religiusitas seseorang mempengaruhi seseorang dalam memandang suatu permasalahan dalam hidupnya. Penderitaan dan penganiayaan adalah salah satu kata kunci dalam surat 1 Petrus ini, ${ }^{2}$ yang disebutkan tidak kurang dari enam belas kali. ${ }^{3}$ Kehidupan yang wajar tidak terlepas dari penderitaan tetapi tetap memahami diri sebagai orang-orang pilihan mampu menikmati hidup dalam kesetiaan kepada Kristus. Nama Petrus dari bentuk Yunani Petros yang berasal dari bahasa Aram. Petrus 1:1 sebutan ini disebutkan kedua-duanya Simon dan Petros. Petrus menggunakan nama ini, bukan Kefas atau Simon, sebab ia sedang menulis kepada orang Kristen yang tersebar di Asia Kecil.

Waktu penulisan Surat ini adalah kira-kira tahun 64 M dimana 1 Petrus memberikan gambaran mengenai tujuan-tujuan penulisan maupun karakteristik dari surat ini. Surat Pertus ini menjelaskan, "Pertama, sebagai jawaban atas keadaan ini sebagaimana yang dialami oleh gereja-gereja di bagian utara Asia Kecil di propinsipropinsi Pontus, Galatia, Kapadokia, Asia, dan Bitinia. Kelima propinsi inilah yang menjadi saksi hidup perubahan sikap pemerintahan Romawi terhadap keberadaan orangorang percaya yang setia kepada Kristus. Dalam hal ini, surat 1 Petrus ini memberikan dorongan kepada penerima surat untuk berpengharapan terus kepada Kristus yang akan memberikan kekuatan kepada mereka, dalam menjalani hari-hari mereka yang sangat berat. Petrus senada dengan Paulus memiliki kerinduan yang sama rela mengorbankan nyawa demi kpenyampaian amanat agung dan tegaknya takhta Kerajaan kasih Allah di

\footnotetext{
${ }^{1}$ J. T. Wnuk, M., \& Marcinkowski, "Do Existential Variables Mediate between Religious-Spiritual Facets of Functionality and Psychological Wellbeing. Journal Religius Health. 7(4).” (2012): 27-36.

2 Stephen W. Paine, "1 Petrus," Dalam Tafsiran Alkitab Wycliffe, ed. Charles F. Pfeiffer dan Everett F. Harrison peny. (Malang: Gandum Mas, 2001), 1288.

${ }^{3}$ Merrill C. Tenney, Survei Perjanjian Baru (Malang: Gandum Mas, 2001), 430.
} 
tengah dunia. ${ }^{4}$ Surat 1 Petrus adalah suatu peringatan dan penghiburan sebagai persiapan bagi keadaan darurat yang akan segera datang. Resilensi adalah kemampuan untuk beradaptasi dan tetap teguh dalam situasi yang sulit ${ }^{5}$

\section{METODOLOGI}

Penelitian ini menggunakan pendekatan kualitatif dengan inti utama ialah pada tujuan mengeksplorasi dan pemahaman data secara lebih mendalam ${ }^{6}$ yang berfokus pada studi pustaka. Metode pembahasan adalah analisis teks pada Alkitab, yaitu tentang makna kata orang-orang terpilih pada 1 Petrus 1:1-2. Penelitian ini menerapkan prinsip-prinsip yang berkaitan dengan hermeneutika Alkitab sehingga menghasilkan paparan yang biblikal. Tujuan Penulisan adalah pemahaman terhadap teks dimana orang Yahudi hidup dalam "perantauan," yang hidup ditengah-tengah orang yang tidak percaya (para pembaca non Yahudi) sehingga pembaca memiliki kemampuan mengembangkan daya tahan dalam menghadapi penderitaan (resiliensi) karena memahami keyakinan diri sebagai orang-orang yang di pilih yang posisiya sudah ditebus terus bertekun menjadikan panggilan dan pemilihan mereka makin teguh

\section{ANALISIS DAN PEMBAHASAN}

Analisis 1 Petrus 1:1, “dari Petrus, rasul Yesus kristus kepada orang-orang pendatang, yang tersebar di Pontus, Galatia, Kapadokia, Asia Kecil dan Britinia. Ptentang orang-orang percaya yang berada di tengah-tengah orang-orang yang tidak percaya. Penerima menunjukkan keadaan mereka di tengah keadaan hidup yang selalu menuntut mereka untuk membuktikan bahwa mereka telah memiliki posisi diri yang jelas di dalam Kristus. Surat 1 Petrus dinyatakan dalam terjemahan baru Lembaga Alkitab Indonesia sebagai orang-orang pendatang." Orang-orang pendatang yang tersebar yang diterjemahkan dalam King James Version sebagai the strangers scattered artinya orangorang asing yang tersebar. NIV sebagai strangers in the world, scattered artinya orang-

\footnotetext{
${ }^{4}$ Desti Samarenna, "Rahasia Allah Dalam Pelayanan Paulus Menurut Efesus 3:8-13," EPIGRAPHE: Jurnal Teologi dan Pelayanan Kristiani 2, no. 1 (2018): 61.

5 "Nhttps://Id.Wikipedia.Org/Wiki/Resiliensi\#cite_note-:0-1."

${ }^{6}$ Agustinus Bandur, Penelitian Kualitatif: Studi Disiplin Keilmuan Dengan Nvivo 12 Plus (Bogor: Mitra Wacana Medika, n.d.), 18.
} 
HARVESTER: Jurnal Teologi dan Kepemimpinan Kristen, Vo 16, No 1, (Juni 2021)

orang asing dalam dunia, tersebar. Jadi ini menunjuk kepada orang-orang yang hidup diluar Palestina

Frasa" kepada orang-orang pendatang," yang berasal dari kata Yunani Parepidemoi yang menekankan kebangsaan asing atau tempat tinggal sementara.Kata ini digunakan hanya tiga kali dalam Perjanjian Baru yaitu dalam Ibrani 11:13; 1 Petrus 1:1;

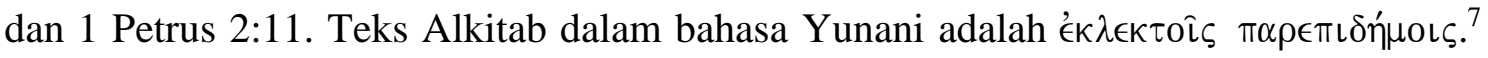

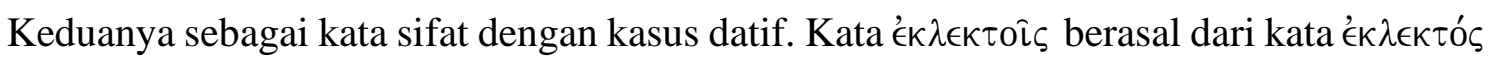
yang berarti "yang terpilih, pilihan." 8 Sedangkan kata $\pi \alpha \rho \epsilon \pi\left\llcorner\delta \eta_{\mu} \mu\llcorner\varsigma\right.$ berasal dari kata

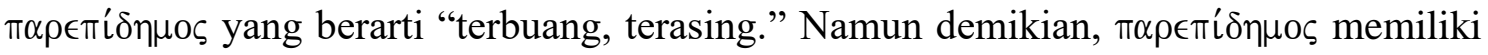

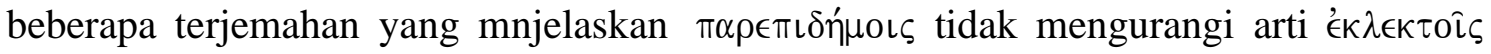
sebab keduanya berfungsi sebagai aposisi. Kedua kata benda ini mengacu kepada persona yang sama, dan bertindak memberi penjelasan lanjut terhadap benda-benda datif yang pertama. ${ }^{9}$ Dalam hal ini, kedua kata sifat datif itu difungsikan sebagai kata benda. Ini adalah fungsi khusus dari kata sifat yang dapat diperlakukan juga kepada kata sifat predikatif.

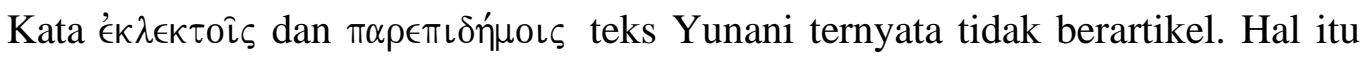
menunjukkan bahwa fungsi kasus datif sebagai obyek tidak langsung pada kedua kata itu tidak sedang membatasi kepentingannya. Kata benda atau kata ganti benda kasus kasus datif adalah orang atau benda yang diberi (menerima) obyek langsung dari kata kerja transitif, atau subyek kata kerja pasif. Dalam terjemahan gagasan ini dapat dinyatakan dengan penambahan preposisi "kepada." Dapat diamati bahwa kedua kata itu saling menjelaskan sifat kewarganegaraan orang asing dan penduduk-penduduk sementara. Pemahaman secara figuratif lebih kuat diperlakukan bagi pengertian ék $\lambda \in \kappa \tau o \hat{\iota} \varsigma$

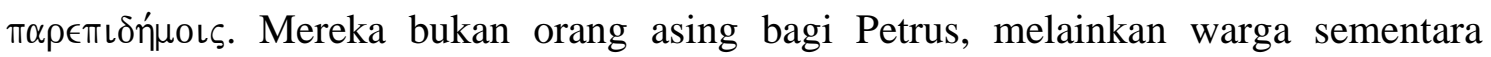
diberbagai propinsi di Asia Kecil. Kewarganegaraan mereka sesungguhnya adalah surga (Fil.3:20). Hal itu perlu terus diingatkan karena mereka tinggal di tengah-tengah masyarakat penyembah berhala, sehingga keberadaan mereka sebagai orang percaya dapat terus dipertahankan, bahkan mereka harus menyadari bahwa tempat tinggal mereka

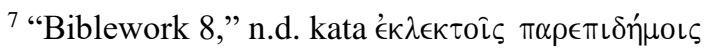

${ }^{8}$ Walter Bauer, A Greek-English Lexicon of the New Testament and Other Early Christian Literature, ed. William F. Arndt dan F. Wilbur Gingrich (Chicago: The University of Chicago Press, 1979), 242.

${ }^{9}$ Petrus Maryono, Gramatika Dan Sintaksis Bahasa Yunani Perjanjian Baru (Yogyakarta: STII, 2008), 38.
} 
yang sebenarnya adalah di surga. Hidup di tengah orang-orang yang tidak pecaya sebagai orang asing, dapat menunjukkan juga bahwa mereka ditempatkan Allah untuk menjadi saksi-Nya. Hal ini merupakan penegasan dari identitas mereka. Petrus dengan sengaja menulis surat ini utnuk menghibur yang sebagian besar bertobat pada hari pentakosta, sebagai yang tersebar dengan makna yang pedih bagi orang-orang Yahudi. Petrus menyesuaikan gambaran ini dengan pembaca non Yahudi. ${ }^{10}$ Bentuk yang digunakan adalah kata benda genitif feminim tunggal, yaitu: $\delta\llcorner\alpha \sigma \pi o \rho \hat{\alpha} \varsigma$. Kata ini berarti penyebaran dan secara figuratif dapat diartikan sebagai orang Kristen yang hidup dalam penyebaran di dunia ini, jauh dari tempat mereka yang menyenangkan." ${ }^{11}$ Kedua arti itu telah dikenakan pada kata $\delta\llcorner\alpha \sigma \pi o \rho \hat{\varsigma} \varsigma$ dalam 1 Petrus 1:1.

Memahami secara utuh pengertian kata $\delta\llcorner\alpha \sigma \pi o \rho \hat{\alpha} \varsigma$ tidak lepas dari penggunaannya secara umum. Penggunaan kata diaspora di luar Perjanjian Baru, menunjukkan bahwa penggunaan kata ini lebih dominan kepada orang Israel yang berdiaspora dalam Septuaginta (LXX) menunjuk kepada orang Israel yang disebar Allah karena dosa-dosa mereka, dan disebar Allah di antara orang-orang bukan Yahudi. Dalam istilah Yunani istilah diaspora menemukan arti baru di mana mereka menemukan rasa bangga dengan status mereka. Penggunaan istilah diaspora dalam Perjanjian Baru ditujukan pada data Alkitab dari Yakobus 1:1 dan 1 Petrus 1:1. Orang Kristen secara umum berlatar belakang Yahudi maupun bukan Yahudi yang ditempatkan Allah di tengah-tengah orang-orang yang tidak percaya. Mereka sementara menjadi orang asing di tempat mereka tinggal, di mana mereka juga tetap mengharapkan untuk tinggal di tempat mereka yang sebenarnya, yaitu Yerusalem surgawi. Hal itu bisa diterima karena ada indikasi pada kata $\delta\llcorner\alpha \sigma \pi о \rho \hat{\varsigma} \varsigma$ sebagai kata benda tidak beratikel menyesuaikan gambaran ini kepada para pembaca nonYahudinya.

Petrus langsung menulis surat kepada 5 jemaat yang dijelasakan sebagai penerima surat ini berada yaitu: Pontus, Galatia, Kapadokia, Asia dan Bitinia. Suratnya bersifat spesifik. Teks tidak menjelaskan bagaimana mereka percaya meskipun diluar Israel. Kemungkinan pada peristiwa Pentoska hadir orang-orang yang berasa dari berbagai daerah pentakosta orang dari berbagai daerah mendengarkan para rasul, termasuk jemaat

\footnotetext{
${ }^{10}$ Stephen W. Paine, "I Petrus," Dalam Tafsiran Alkitab Wycliffe, 3:1294.

${ }^{11}$ Walter Bauer, A Greek-English Lexicon of the New Testament and Other Early Christian Literature, 188.
} 
HARVESTER: Jurnal Teologi dan Kepemimpinan Kristen, Vo 16, No 1, (Juni 2021)

yang dikirimkan surat oleh Petrus walaupun tidak ada hubungan yang dekat. Petrus yang telah diubahkan, memberikan semangat dan kekuatan kepada saudara-saudara yang tersebar di daerah-daerah konflik itu. Daerah-daerah itu menjadi wilayah kekuasaan bangsa Roma, yang pada akhirnya menjadi daerah konflik berdasarkan kepentingan antara pemerintahan Romawi dan oposisi Yahudi yang tidak menginginkan kehadiran kekristenan. Petrus menyebut daerah-daerah ini dalam suatu usaha untuk memberikan dukungan, bahkan perhatiannya pada orang-orang percaya bahwa mereka tidak sedang menderita sendiri, urutan daerah yang disebutkan Petrus merupakan urutan dari sisi berat ringannya penderitaan.

Dalam 1 Petrus 1:1 mencatat bahwa Pontus sebagai daerah pertama dalam urutan daerah yang disebut Petrus, dimana penerima surat ini tersebar. Pontus, semula adalah nama suatu laut (Laut Euxine, atau Laut Hitam), ditemukan oleh orang Persia Achaemenid di timurlaut Asia Kecil, dari Laut Hitam sampai Caucasus. Setelah penaklukan Pompey, bagian itu dibuat sebuah propinsi Roma. ${ }^{12}$ Orang Yahudi dari Pontus (Kis. 2:9; 18:2) mungkin berasal dari negara pantai bawahan pemerintahan Yunani. Asal mula jemaat Kristen di sana tidak diketahui, tapi jemaat itu adalah penerima Surat 1 Petrus (1 Ptr. 1:1). ${ }^{13}$ Pontus terbagi dua, yaitu bagian barat yang dikuasai bangsa Romawi dan bagian timur yang tetap menjadi daerah Yunani. Sedangkan asal mula orang Kristen di Pontus bagian barat, diperkirakan berasal dari bagian timur yang dikuasai oleh Yunani. Di tengah konflik, orang Kristen tetap memandang pada kehendak Tuhan, serta menyatakan bahwa aturan yang tertinggi mereka adalah kesetiaan kepada Kristus dan menolak segala bentuk pemujaan kepada berhala maupun Kaisar. Penderitaan yang dialami oleh orang-orang Kristen di Pontus itu meluas ke propinsi-propinsi yang di bawah kekuasaan Romawi. Kebijakan kekaisaran Romawi itu sangat mutlak. Hal ini menjadi tantangan bagi orang-orang Kristen di Pontus maupun di daerah-daerah lain yang telah menjadi daerah kekuasaan mereka.

Galatia, satu di antara propinsi Romawi. Pada tahun 64 sM, Galatia menjadi daerah protektorat Romawi. Sesudah kematian Amintas, rajanya yang terakhir, status Galatia menjadi propinsi penuh kekaisaran Romawi (25 sM). Propinsi baru ini tidak

\footnotetext{
12 Ibid.

${ }^{13}$ E. A Judge, “Pontus, ” Dalam Ensiklopedi Alkitab Masa Kini, ed. M. H Simanungkalit, J. D Dougl. (Jakarta: Yayasan Komunikasi Bina Kasih/OMF, n.d.), 2:274.
} 
hanya meliputi daerah etnisnya yang lama, tapi juga bagian-bagian dari Pontus, Frigia, Likonia, Pisidia, Paflagonia dan Isauria. ${ }^{14}$ Keberadaan orang Kristen di Galatia, tidak jauh berbeda dengan orang Kristen di Pontus. Mereka dinyatakan oleh Perjanjian Baru sebagai orang Kristen yang bertobat. Hal ini mengindikasikan bahwa kesetiaan mereka kepada Kristus tidak diragukan. Oleh karena itu, ketika kebijakan pemerintahan Romawi raya dijalankan maka mereka pun tidak mau menyenangkan manusia. Konsekuensinya, mereka berhadapan dengan tekanan maupun penganiayaan dari penguasa pemerintahan Romawi. Penulis Surat 1 Petrus adalah satu pemimpin pilar di Gereja (Gal. 2:9). Ia menjadi pembicara utama mewakili para murid, seperti terlihat dalam rapat pemilihan pengganti Yudas Iskariot (Kis. 1:15-22), pada hari Pantekosta (2:14-36), dan juga dalam konggres Yerusalem (Kis. 15:7-11). Ia juga merasa sebagai Rasul bagi orang Yahudi (1 $\operatorname{Ptr} 1: 1)^{15}$

Kapadokia adalah di bagian dalam Asia Kecil. ${ }^{16}$ Letaknya sangat strategis sebagaimana dijelaskan berikut ini karena menjadi jalur perdagangan antara Asia Tengah dan pelabuhan-pelabuhan Laut Hitam melaluinya dan dapat dengan mudah dicapai dari Tarsus melalui Pintu Gerbang Kikilia. ${ }^{17}$ Keberadaan orang Kristen di daerah ini ditandai dengan kehadiran mereka di Yerusalem pada hari Pentakosta (Kis. 2:9). Beberapa pendatang yang tersebar, yang kepadanya Petrus menulis surat-suratnya, hidup di Kapadokia. Orang percaya disana juga masih dibawak kekuasaan Romawi.

Asia adalah suatu propinsi di bagian barat Asia Kecil. ${ }^{18}$ Wilayah itu mencakup beberapa negara bagian Yunani, yang pada abad $3 \mathrm{sM}$ jatuh di bawah kekuasaan raja Pergamos. Pemujaan Roma dan Kaisar Agustus, yang pada awalnya berpusat di Pergamum. ${ }^{19}$ Mula-mula agama Kristen hanya terdapat di pusat administratif propinsi. Ketiga pusat besar, yaitu Pergamun, Smirna dan Efesus, mempunyai jemaat. Di luar itu ada jemaat di dua tempat, yaitu dekat kota sidang pengadilan, Sardis, di lembah Hermon

\footnotetext{
${ }^{14}$ W. W Wessel, “Galatia," Dalam Ensiklopedi Alkitab Masa Kini, ed. M. H Simanungkalit pen., peny., J. (Jakarta: Yayasan Komunikasi Bina Kasih/OMF, 1997), 1:321.

${ }^{15}$ Paul Enns, The Moody Handbook of Theology (Chicago: Moody Press, 1989), 126.

${ }^{16}$ Walter Bauer, A Greek-English Lexicon of the New Testament and Other Early Christian Literature, 403.

${ }^{17}$ J. W Meiklejohn, "Kapadokia," Dalam Dalam Ensiklopedi Alkitab Masa Kini, ed. M. H Simanungkalit pen., peny., J. (Jakarta: Yayasan Komunikasi Bina Kasih/OMF, 1997), 1:517.

${ }^{18}$ Walter Bauer, A Greek-English Lexicon of the New Testament and Other Early Christian Literature, 116.

${ }^{19}$ E. A Judge, “Asia,” Dalam Dalam Ensiklopedi Alkitab Masa Kini, ed. M. H Simanungkalit pen., peny., J. (Jakarta: Yayasan Komunikasi Bina Kasih/OMF, 1997), 1:103.
} 
HARVESTER: Jurnal Teologi dan Kepemimpinan Kristen, Vo 16, No 1, (Juni 2021)

(Tiatira dan Filadelfia adalah kota-kota penting dalam daerah yang sama) dan Laodikia (di Sungai Likus) pada hulu lembah Meander (dengan kota-kota kecil Kolose dan Hierapolis yang dekat). ${ }^{20}$ Kondisi ini menjelaskan penderitaan orang-orang Kristen di propinsi ini. Inilah penderitaan sejati dari penerima Surat 1 Petrus di Asia.

Bitinia adalah suatu propinsi di bagian utara dari Asia Kecil. Daerah pantai Bosporus di wilayah Asia. Oleh rajanya yang terakhir diwariskan kepada bangsa Roma pada tahun 74 sM dan selanjutnya diatur bersama Pontus sebagai satu propinsi. Daerah ini dibagi-bagi di antara sejumlah republik Yunani yang makmur. Menarik perhatian Paulus (Kis. 16:7), meskipun keinginannya untuk memberitakan Injil di sana kelihatannya tidak pernah terpenuhi. Tapi orang-orang lain melakukannya (1Ptr. 1:1) dan sekitar tahun $111 \mathrm{M}$ di sini ada satu gereja yang teratur baik, yang bahkan meluas ke daerah pedesaan dan oleh karena itu menimbulkan banyak penentangan dari masyarakat setempat. ${ }^{21}$ Jadi, di Pontus, Galatia, Kapadokia, Asia kecil dan Bitinia (ay. 1b) ini menunjuk pada gereja-gereja di Galatia dan Asia, yang diantaranya ada yang didirikan oleh Rasul Paulus. Tujuan utama surat Petrus kepada orang-orang Yahudi yang tersebar diluar Palestina yang menunjukkan bahwa mereka sedang menderita. Secara khusus surat 1 Petrus membahas tentang penderitaan.

Analisis 1 Petrus 1:2, "yaitu orang-orang yang dipilih, sesuai dengan rencana Allah, Bapa kita, dan yang dikuduskan oleh Roh, supaya taat kepada Yesus Kristus dan menerima percikan darahNya. Kiranya kasih karunia dan damai sejahtera makin melimpah atas kamu." Penerima Surat 1 Petrus dijelaskan pada ayat 2a-2b “yaitu orangorang yang dipilih, sesuai dengan rencana Allah, Bapa kita, dan yang dikuduskan oleh Roh”. Terjemahan Baru itu menekankan pada “orang-orang yang terpilih" sebagai kata kuncinya. Dalam NIV menggunakan terjemahan to God's elect artinya kepada orangorang pilihan Allah. Dalam Perjanjian Lama, istilah "bangsa pilihan" ditujukan kepada Israel (Ul. 7:6; Maz. 105:6;43; Yes. 45:4) tetapi karena Israel menolak maka istilah itu lalu dipindahkan kepada gereja (Mat. 21:41; Mark. 12:9; Luk. 20:16). Menarik, pemilihan Allah terhadap orang percaya saat ini berbeda dengan pemilihan terhadap Israel pada jaman dulu.

\footnotetext{
20 "Biblework 8." "Asia," dalam Bible Dictionaries.

${ }^{21}$ E. A Judge, “Bitinia,” Dalam Ensiklopedi Alkitab Masa Kini, ed. Broto Semedi, J. D Dougl. (Jakarta: Yayasan Komunikasi Bina Kasih/OMF, 1997), 1:196.
} 


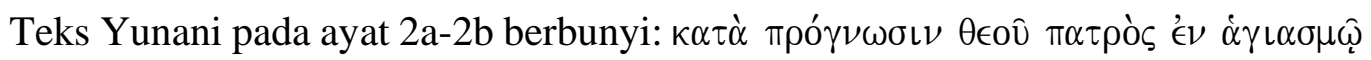

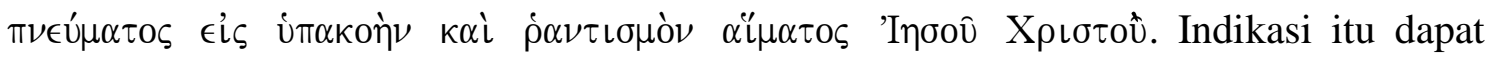
dipahami dengan sintaksisnya yang menjelaskan tiga anak kalimat yang ditandai dengan kehadiran tiga kata depan dalam posisi menjelaskan kata sebelumnya. Kata yang

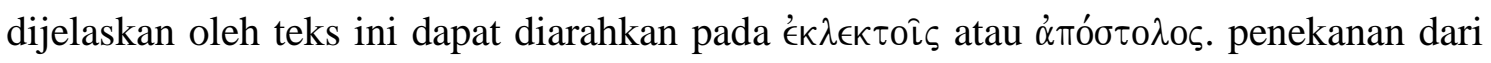

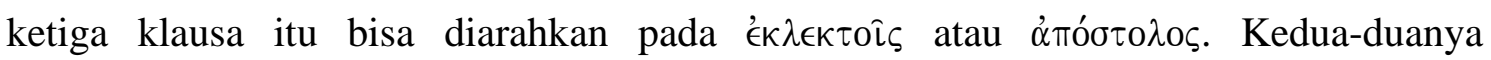
memungkinkan untuk mendapatkan penekanan dari ketiga klausa itu. Namun yang lebih

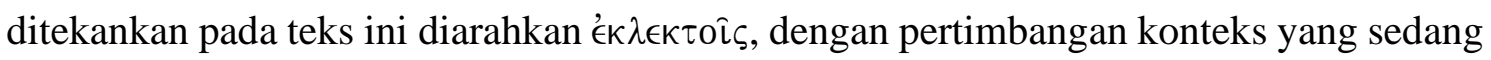
memberikan semangat kepada orang-orang Kristen yang merasa makin lama makin sendirian ini. Petrus menjelaskan keberadan orang percaya dan tanggung jawab penerima surat ini. '́લ $\lambda \epsilon \kappa \tau 0 \hat{\iota} \varsigma$, yaitu identitas penerima surat ini. Mereka adalah orang yang tersebar di negeri asing, dan bagi penduduk negeri mingkin dianggap sebagai gangguan yang menyebabkan mereka menderita. Tetapi sekarang, mereka diingatkan akan posisinya bahwa dari sudut Allah, mereka adalah orang-orang pilihan Allah.

Frasa "sesuai dengan rencana Allah" Kata rencana merupakan terjemahan Yunani Prognosin berarti pengetahuan lebih dulu. Penggunaan kata depan $\kappa \alpha \tau \grave{\alpha}$ dihubungkan dengan '́K $\lambda \epsilon \kappa \tau o \hat{\imath} \varsigma$ yang lepas dan tidak menggunakan artikel dalam ayat 1, 2 dimana dalam surat Petrus lebih sering menggunakan kata benda daripada kata kerja. Kata benda yang

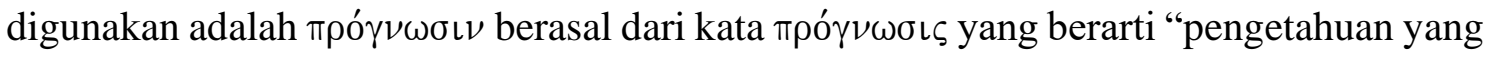
terdahulu, pengetahuan masa lalu, apa yang dikenal melewati waktu. Hal itu menunjukkan bahwa Petrus mengakui keberadaan penerima surat sebagai orang-orang yang terpilih. Pilihan itu ditetapkan oleh Allah Bapa di masa lalu. Dalam teks Yunani, Allah Bapa merupakan kata benda anarthous dan berkasus genitif. Selanjutnya, patêr diaplisikan juga pada Allah di dalam 1 Petrus 1:3, 17 seperti sering digunakan oleh Paulus (Rm.1:7). Kehadiran Tritunggal (Allah Bapa, Yesus Kristus, Roh Kudus) banyak digunakan Petrus dalam suratnya. Hal ini menunjukkan bahwa Petrus mengungkapkan kebenaran yang lama tersembunyi, dan juga mengaplikasikan dalam kehidupan orang percaya bahwa merekalah yang terpilih itu. Pada dasarnya Allah Bapa menetapkan mereka di masa lampau, tetapi pengalaman individu dan masyarakat merupakan aplikasi bagi penerima surat ini sebagai orang-orang yang terpilih. Petrus mau meyakinkan penerima surat ini bahwa posisi mereka sekarang sudah ditetapkan dari masa lampau oleh 
HARVESTER: Jurnal Teologi dan Kepemimpinan Kristen, Vo 16, No 1, (Juni 2021)

Allah Bapa. Mereka sesungguhnya adalah orang-orang yang telah dipilih dan dikhususkan oleh Dia yang perkenan-Nya adalah yang utama. ${ }^{22}$ Kalau ayat 2a berbicara tentang pemilihan, maka ayat $2 \mathrm{~b}$ berbicara tentang tujuan pemilihan, yaitu supaya taat kepada Kristus. Taat atau menjadi baik bukan alasan pemilihan tetapi tujuan pemilihan. Efesus 1:4: "Allah telah memilih kita sebelum dunia dijadikan, supaya kita kudus dan tak bercacat di hadapanNya. Penetapan Allah menuntut tanggapan orang percaya, serta tanggapan posisitif terhadap karya Roh Kudus yang memiliki makna disiplin yang dapat diterapkan dalam kehidupan orang percaya. Allah Bapa memilih sesuai dengan rencanaNya menegaskan status mereka yaitu Allah Bapa memilih mereka dengan kebijaksanaanNya yang tidak mungkin bisa salah. Kehendak Allah tepat sekali bagi kehidupan orang percaya.

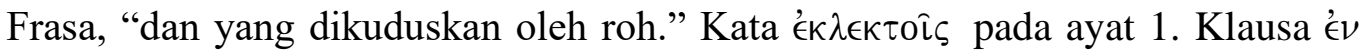
$\dot{\alpha} \gamma\left\llcorner\alpha \sigma \mu \hat{\varphi} \pi \nu \in \dot{\mu} \mu \alpha \tau o \varsigma\right.$ dapat diartikan "di dalam pengabdian Roh." ${ }^{23}$ Kata $\dot{\alpha} \gamma\llcorner\alpha \sigma \mu \hat{\omega}$ ternyata memberikan warna khusus pada klausa itu. Kata itu dapat diartikan seperti proses membuat persembahan kudus, penyucian; dan seperti sasaran moral dari proses kekudusan, perilaku yang benar (Rm. 6:22). ${ }^{24}$ Menekankan pada penyucian. Proses yang dikerjakan Roh Kudus dalam kehidupan orang percaya sampai ia memperoleh secara utuh bagiannya sebagai umat Allah. Roh Kudus menjadikan orang percaya dalam menemukan keberadaannya di dalam Kristus. Selanjutnya orang percaya harus terus hidup dalam penyucian diri, menggunakan hata Hagiasmos berasal dari kata kerja, istilah ini berarti "penyucian." Hanya pribadi yang suci yang dapat "menyucikan," jadi penyucian ilahi mendahului proses penyucian manapun (Why. 22:11). Pengertian lain bahwa penyucian telah dikerjakan dalam diri orang percaya dalam anugerah-Nya. Oleh karena itu, orang percaya harus memberi respon terhadap anugerah-Nya itu.Pernyataan Petrus bahwa status penerima surat ini adalah orang-orang yang terpilih. Memilih mereka adalah di dalam bidang dari pekerjaan Roh Kudus yang sesungguhnya. ${ }^{25}$ Roh Kudus di dalam diri orang percaya menggunakan proses penyucian, sehingga orang percaya menemukan pemahaman mengenai karya penebusan Kristus. Penyucian yang dikerjakan Roh Kudus

\footnotetext{
22 Stephen W. Paine, “1 Petrus,” Dalam Tafsiran Alkitab Wycliffe, 3:995.

${ }^{23}$ Walter Bauer, A Greek-English Lexicon of the New Testament and Other Early Christian Literature, 9.

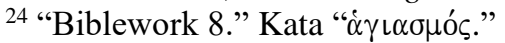

25 J. H. A. Hart, “1 Peter," Dalam The Expositor's Greek Testament, ed. peny. W. Robertson Nicoll (Grand Rapids: Wm. B. Eerdmans Publishing Company, 1970), 40.
} 
itu, pada akhirnya menjadikan masyarakat baru dalam pandangan Allah, yaitu orangorang yang terpilih mempunyai kemampuan hidup kudus di tengah-tengah orang-orang yang tidak kudus atau tidak percaya kepada Kristus sebagai Tuhan dan Juruselamatnya

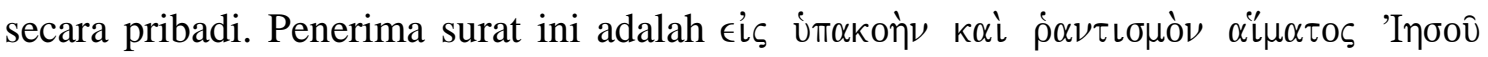

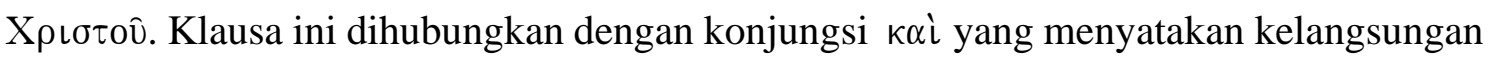
pendapat yang diterjemahkan "dan". ${ }^{26}$ Indikasinya adalah dari klausa itu membicarakan dua hal yang berhubungan erat. Sehingga klausa itu dapat diterjemahkan "supaya taat

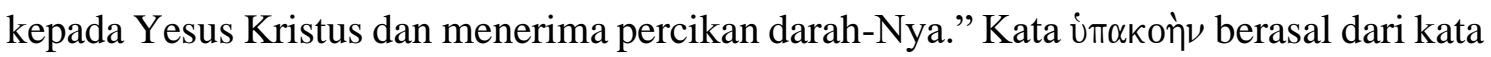
ن்ккоฑ́, artinya adalah: pertama, ketaatan, ketundukan, pemenuhan (Rm. 16:19),

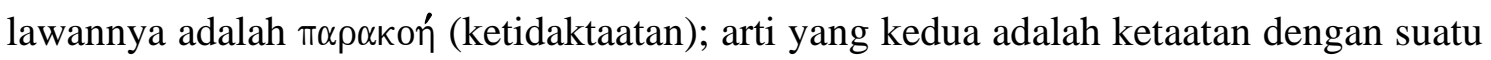
permintaan (Flm. 21). ${ }^{27}$ Dalam hal ini, ketaatan kepada Allah dan perintah-perintah-Nya merupakan arti yang utama dari u̇đaкớ. Jadi, orang-orang yang dipilih oleh Allah, oleh Roh Kudus dipisahkan dari yang lain, dan dikhususkan bagi Allah.

Frasa, "menerima percikan darahNya." Kata yang kedua adalah $\dot{\rho} \alpha \nu \tau \iota \sigma \mu \grave{o} \nu$ dari $\grave{\rho} \alpha \nu \tau \iota \sigma \mu o ́ s$. Kata ini digambarkan seperti ritual pemercikan darah. Secara figuratif, kata

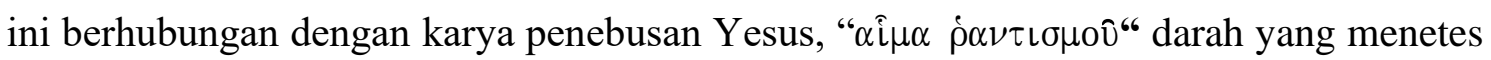
menyingkirkan dosa (Ibr. 12:24). ${ }^{28} 1$ Petrus 1:2 menunjukkan bahwa orang Kristen

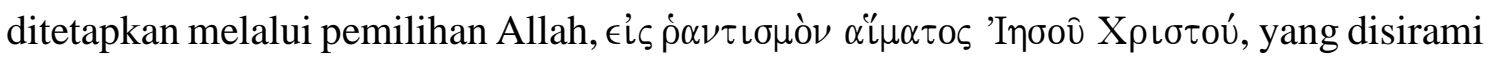
dengan darah Kristus sehingga dosa-dosa mereka ditebus. Yesus Kristus berkorban bagi orang-orang percaya sebagai rancangan Allah di masa lalu, dimana Allah telah menetapkannya dan bersedia untuk menyatakannya untuk menyucikan orang-orang yang percaya kepada-Nya. ${ }^{29}$ Ini menunjuk pada pengampunan dosa. Pengmpunan hanya karena pengornbanan Yesus di atas kayu salib.

Frasa "kiranya kasih karunia dan damai sejahtera makin melimpah atas kamu." Penetapan status penerima Surat 1 Petrus memberikan gambaran yang jelas mengenai

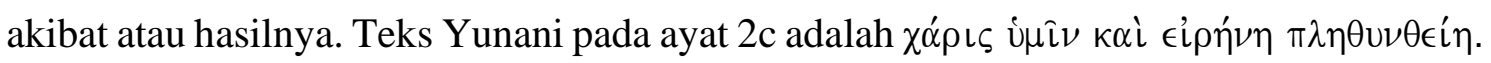
Penggunaan salam itu telah digunakan secara luas dalam Alkitab, secara khusus dalam Surat-surat. Kata $\pi \lambda \eta \theta v \nu \theta \epsilon i \eta \eta$ merupakan kata kerja aoris pasif optatif orang ketiga

\footnotetext{
${ }^{26}$ Petrus Maryono, Gramatika Dan Sintaksis Bahasa Yunani Perjanjian Baru, 5.

27 "Biblework 8." Dalam "i்akoń."

${ }^{28}$ Ibid. Kata " $\rho \alpha \nu \tau \iota \sigma \mu o ́ s$

${ }^{29}$ D.H. Wheaton, Tafsiran Alkitab Masa Kini, ed. M.Rikin (Jakarta: Yayasan Komunikasi Bina Kasih/OMF, 2013), 3:816.
} 
HARVESTER: Jurnal Teologi dan Kepemimpinan Kristen, Vo 16, No 1, (Juni 2021)

tunggal. ${ }^{30}$ Optatif, sama seperti subyungtif, menyatakan suatu sikap ketidakpastian. Hanya saja dalam, dalam optatif realisasi tindakan itu didasarkan pada landasan subyektif; karena itu, kemungkinannya menjadi semakin kecil. ${ }^{31}$ Fungsi dalam penggunaannya itu menunjukkan harapan atau doa Petrus pada bagian ini adalah semoga kasih karunia dan damai sejahtera dilimpahkan kepada penerima surat ini. Kata $\pi \lambda \eta \theta v \nu \theta \epsilon$ í merupakan kata kerja aoris. Pada umumnya penggunaan aoris sejalan dengan hakekat dasar kala ini. Peyuguhan peristiwa itu disampaikan dari sudut pandang pembicara; yang kemungkinan sengaja dipilih, agar tidak seutuhnya menampilkan realita yang sebenarnya. Transitif yaitu bersangkutan dengan kata kerja yang memerlukan objek dari kata $\pi \lambda \eta \theta v \nu \omega \hat{\omega}$ yang diterjemahkan "melipatgandakan," yang dihubungkan dengan ayat $2 \mathrm{c}$ diterjemahkan "semoga kasih karunia dan damai sejahtera menjadi milikmu di dalam ukuran yang semakin besar." Tindakan itu dilihatnya sebagai satu keseluruhan. Bentuk aoris ini dikenal dengan aoris konstatif atau disebut juga aoris kompleksif. ${ }^{32}$ Kelangsungan atau penyelesaian dari tindakan melipatgandakan atau meningkatkan tidak terlalu ditekankan dalam hal ini. Jadi ada dua ungkapan pada tujuan penetapan keadaan mereka.

Harapan Petrus bagi penerima suratnya mereka dilimpahi Allah dengan kasih karunia yang melimpah. Dalam hal ini, kata $\chi \alpha \dot{\rho} \iota \varsigma$ yang dipakai Petrus pada suratnya ini menunjukkan pengertian yang lebih dalam. Dalam teks ini menderita dipahami sebagai kasih karunia (2:19-20), merupakan ungkapan dari doa atau harapan Petrus ketika ia memperhatikan kondisi yang terus berkembang, dimana penerima suratnya sedang dalam konflik yang menekan mereka. Hal kedua yang menjadi doa dan harapan rasul Petrus adalah damai sejahtera Allah dilimpahkan kepada penerima surat ini secara melimpah.

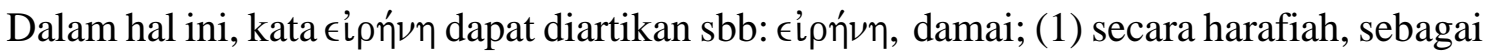

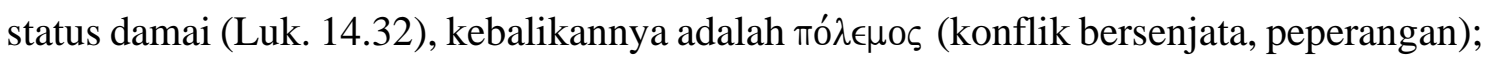
yang secara kiasan, sebagai suatu persetujuan di antara orang-orang (Yak. 3.18), berlawanan dengan $\delta\llcorner\alpha \mu \epsilon \rho \iota \sigma \mu o ́ \varsigma$ (divisi, perselisihan); (2) sebagai salam sesuai dengan kata Ibrani shalom: sehat, sejahtera, damai (kepada kamu) (1Timotius 1:2); (3) sebagai

\footnotetext{
30 "Biblework 8."Kata $\pi \lambda \eta \theta v \nu \theta \epsilon i ́ \eta, "$

${ }^{31}$ Petrus Maryono, Gramatika Dan Sintaksis Bahasa Yunani Perjanjian Baru, 104.

${ }^{32}$ W.E Vine; Merrill F. Unger; William White, Vine's Expository Dicrionary of Biblical Words: A Complete Expository Dictionaty of The Old and New Testamens IIn One Volume (New York: Thomas nelson Publishers, 1978), 277.
} 
disposisi religius yang ditandai oleh ketenangan, kebebasan dari ketertarikan (Rm. 15:13). ${ }^{33}$ Hubungan di antara kedua istilah itu dijelaskan Perjanjian Baru, di mana ungkapan Ibrani: eirene mempunyai pemakaian dan pengertian yang hampir sama dengan ungkapan Ibrani: shalom di mana ungkapan itu dinyatakan dalam Septuaginta; bandingkan Luk. 19:42, "kita masih mengharapkan damai" sampai datangnya Kristus (Luk. $1: 74,79 ; 12: 51$ ) dan juga pemenuhannya dalam pengertian rohani yang lebih tinggi. Damai sejahtera yang dimaksudkan Petrus di sini adalah damai sejahtera dalam hati orang percaya yang penuh dengan Roh Kudus. Orang percaya yang sedang menderita karena realitas kondisi yang ada, didoakan oleh rasul Petrus supaya mereka memiliki damai sejahtera. Berkat-berkat rohani tetap dilimpahkan secara melimpah di dalam hidup orang percaya walaupun situasi menekan mereka.

\section{KESIMPULAN}

Surat Petrus 1:1-2 ditulis untuk gereja di lima propinsi barat laut, Asia Kecil. Pertobatan mereka kepada Kristus menyebabkan mereka terasing dari budaya dan temanteman mereka. Ditengah-tengah fitnah, pengucilan dan situasi yang sulit Petrus mendorong untuk memahami resiliensi (penderitaan) sebagai orang-orang pilihan tetap dalam kontrol dan kendali Allah. Ada hal-hal yang dapat dipelajari dari teks ini dimana Hamba Tuhan mempunyai hak dan kewajiban menjelaskan secara lengkap ajaran-ajaran Kristen kepada semua orang yang baru bertobat dan mendorong agar berperilaku kudus dan setia sehingga mereka tetap hidup dalam damai sejahtera dan mampu menjawab segala fitnah dan celah dari orang-orang yang tidak percaya kemudian mempersiapkan orang percaya menghadapi penderitaan supaya bersabar dan bertekun dalam iman, agar segala penganiayaan dan malapetaka yang menimpa tidak sampai membuat mereka murtad dari Kristus dan injil. Penderitaan orang pilihan sesuai dengan rencana Allah oleh karena itu tetap taat karena untuk itulah orang percaya dipilih karena Allah memilih orang percaya karena dikasihi lebih dulu itu adalah pemilihan kekal. Oleh karena itu, orang percaya sebagai orang-orang pilihan terus berupaya mengembangkan daya tahan terhadap penderitaan dengan cara menyadari sebagai orang-orang pilihan sifatnya kekal bukan

\footnotetext{
${ }^{33}$ Ibid., 464.
} 
sementara. Penyucian Roh Kudus adalah kekuatan untuk hidup suci ditengah dunia dan kedamaian orang percaya berasal dari Allah.

\section{KEPUSTAKAAN}

Bandur, Agustinus. Penelitian Kualitatif: Studi Disiplin Keilmuan Dengan Nvivo 12 Plus. Bogor: Mitra Wacana Medika, n.d.

D.H. Wheaton. Tafsiran Alkitab Masa Kini. Edited by M.Rikin. Jakarta: Yayasan Komunikasi Bina Kasih/OMF, 2013.

E. A Judge. “Asia,” Dalam Dalam Ensiklopedi Alkitab Masa Kini. Edited by M. H Simanungkalit pen. Peny., J. Jakarta: Yayasan Komunikasi Bina Kasih/OMF, 1997.

—. "Bitinia,” Dalam Ensiklopedi Alkitab Masa Kini. Edited by Broto Semedi. J. D Dougl. Jakarta: Yayasan Komunikasi Bina Kasih/OMF, 1997.

—. "Pontus," Dalam Ensiklopedi Alkitab Masa Kini. Edited by M. H Simanungkalit. J. D Dougl. Jakarta: Yayasan Komunikasi Bina Kasih/OMF, n.d.

J. H. A. Hart. “1 Peter,” Dalam The Expositor's Greek Testament. Edited by peny. W. Robertson Nicoll. Grand Rapids: Wm. B. Eerdmans Publishing Company, 1970.

J. W Meiklejohn. “Kapadokia,” Dalam Dalam Ensiklopedi Alkitab Masa Kini. Edited by M. H Simanungkalit pen. Peny., J. Jakarta: Yayasan Komunikasi Bina Kasih/OMF, 1997.

Merrill C. Tenney. Survei Perjanjian Baru. Malang: Gandum Mas, 2001.

Paul Enns. The Moody Handbook of Theology. Chicago: Moody Press, 1989.

Petrus Maryono. Gramatika Dan Sintaksis Bahasa Yunani Perjanjian Baru. Yogyakarta: STII, 2008.

Samarenna, Desti. "Rahasia Allah Dalam Pelayanan Paulus Menurut Efesus 3:8-13." EPIGRAPHE: Jurnal Teologi dan Pelayanan Kristiani 2, no. 1 (2018): 61.

Stephen W. Paine. “1 Petrus,” Dalam Tafsiran Alkitab Wycliffe. Edited by Charles F. Pfeiffer dan Everett F. Harrison peny. Malang: Gandum Mas, 2001.

W. W Wessel. "Galatia," Dalam Ensiklopedi Alkitab Masa Kini. Edited by M. H Simanungkalit pen. Peny., J. Jakarta: Yayasan Komunikasi Bina Kasih/OMF, 1997. W.E Vine; Merrill F. Unger; William White. Vine's Expository Dicrionary of Biblical 
Words: A Complete Expository Dictionaty of The Old and New Testamens IIn One Volume. New York: Thomas nelson Publishers, 1978.

Walter Bauer. A Greek-English Lexicon of the New Testament and Other Early Christian

Literature. Edited by William F. Arndt dan F. Wilbur Gingrich. Chicago: The University of Chicago Press, 1979.

Wnuk, M., \& Marcinkowski, J. T. "Do Existential Variables Mediate between ReligiousSpiritual Facets of Functionality and Psychological Wellbeing. Journal Religius Health. 7(4)." (2012).

"Biblework 8," n.d.

"Nhttps://Id.Wikipedia.Org/Wiki/Resiliensi\#cite_note-:0-1." 